\title{
Symposium
}

\section{Plant Diseases Impacting Resource-Poor Farmers in Developing Countries: Can They Be Successfully Controlled?}

\section{H. J. Dubin, Organizer}

Publication no. D-2004-0206-030

The symposium focused on the realities of some significant diseases in developing countries and successes and problems in their management. An overview of sustainable disease management is given, and the speakers, all experts in their field, cover a range of diseases, hosts, and geographical areas in the developing world.

The speakers concentrated on methodology, innovativeness, sustainability and profitability, and problems and issues related to disease control as well as the future of disease management for resource-poor farmers.

Symposia of this type are particularly important in today's globalized economy and ever-shrinking world. We believe it is imperative that American Phytopathological Society members are exposed to the realities of farmers in developing countries and how we can help them; and, conversely, how they can help us. This symposium contributes to that end. 